\title{
ALGEPS
}

REVISTA DE GEOLOGIA, SÈRIE B no 596 - Juliol del 2012

\section{RECORRIDO DESDE ANDORRA A CRIVILLÉN, LA VENTA DE LA PINTADA I A EJULVE, A TRAVÉS DEL PATRIMONIO GEOLÓGICO Y MINERO DE LAS COMARCA DE ANDORRA - SIERRA DE ARCOS}

Josep M. Mata-Perelló

Aquest recorregut va ésser experimentat amb docents el dia 1 DE SETEMBRE DEL 2010 


\section{RECORRIDO DESDE ANDORRA A CRIVILLÉN, LA VENTA DE LA PINTADA I A EJULVE, A TRAVÉS DEL PATRIMONIO GEOLÓGICO Y MINERO DE LAS COMARCA DE ANDORRA - SIERRA DE ARCOS}

\section{ADVERTENCIAS PREVIAS}

Como en otros recorridos de RECONOCIMIENTO GEOLÓGICO (o de RECONOCIMIENTO GEOLÓGICO Y MINERO), el recorrido se compondrá de diversas PARADAS. En este caso serán ocho.

Por otra parte, habrá que tener en cuenta, en todo momento, especialmente antes de empezar los recorridos de los diferentes tramos, el estado de los caminos y carreteras, por donde transitará el recorrido. Al respecto, cabe decir que prácticamente todos estos tramos se halla en buenas condiciones.

Finalmente, como ya hacemos en otros recorridos similares, queremos decir que hace falta tener un cuidado muy especial en el respeto a la naturaleza, a lo largo de todo el recorrido del itinerario, y también fuera de él.

\section{BREVE INTRODUCCIÓN GEOLÓGICA}

El recorrido de este itinerario, se desarrollará íntegramente por una de las tres unidades geológicas que constituyen el suelo y el subsuelo de Aragón. Concretamente por el Sistema Ibérico o Cordillera Ibérica.

Así, a lo largo de todo de todo el recorrido del itinerario, se irán encontrando afloramientos de los materiales mesozoicos, fundamentalmente del Cretácico. Y más concretamente del Albiense, en la mayoría de las ocasiones. Asimismo, a menudo, encontraremos afloramientos de los materiales detríticos cuaternarios, por encima de los anteriores.

\section{BREVE INTRODUCCIÓN GEOGRÁFICA}

El recorrido del presente itinerario se efectuará exclusivamente por una comarca aragonesa, la de la Andorra - Sierra de Arcos. Así, se iniciará en la propia capital comarcal, en la población de Andorra, en donde se efectuará una parada, coincidente con la primera del ITINERARIO 1. 
Luego, el recorrido se irá dirigiendo hacía el Sur (en ocasiones hacía el SW), yendo hacía la población de Crivillén, por donde se efectuaran diversas paradas, especialmente en los Mases de Crivillén. Tras ello, el recorrido se dirigirá hacía la Venta de la Pintada (del municipio de Gargallo). Finalmente, se dirigirá hacía Ejulve, finalizando el recorrido en este municipio.

En este recorrido, se circulará por los términos municipales de: Andorra, Alloza, Crivillén, Gargallo y Ejulve. Todos ellos de la comarca de Andorra - Sierra de Arcos; aunque el recorrido finalizará muy cerca de la del Maestrazgo.

Esta comarca, gravita en torno a dos ríos de la misma cuenca: el Martín y el Guadalope (con su afluente, el Guadalopillo).

\section{OBJETIVOS GENERALES DE ESTE ITINERARIO}

En este itinerario, los objetivos generales que se han de conseguir, se pueden concretar en los siguientes aspectos:

1.- Estudio y reconocimiento de los materiales mesozoicos (en buena parte del Cretácico y en menor del Triásico y Jurásico, según los lugares) situados en el Sistema Ibérico, que iremos encontrando a lo largo de todo el recorrido del itinerario.

2.- Visión de algunas de las antiguas explotaciones encontradas a lo largo del recorrido del itinerario. En concreto de:

4A) de las explotaciones de lignito, situadas en los municipios de Andorra, al principio del recorrido, entre los afloramientos mesozoicos del Albiense.

4B) de las explotaciones de caolín, situadas en los Mases de Crivillén (Crivillén) y en la Venta de la Pintada (Gargallo), entre los afloramientos mesozoicos del Albiense.

4C) de las antiguas explotaciones de los minerales de manganeso, situadas en los Mases de Crivillén, entre los afloramientos mesozoicos del Aptiense.

4D) de las antiguas explotaciones de calizas mesozoicas situadas en el municipio de Ejulve.

3.- Observación del impacto producido por las actividades mineras. I de las restauraciones realizadas para paliar este impacto.

4.- Visión de los diferentes lugares directamente relacionados con el Patrimonio Geológico y Minero que iremos encontrando a lo largo del recorrido del presente itinerario.

\section{ANTECEDENTES BIBLIOGRÁFICOS}

En relación con este itinerario, no conocemos ningún antecedente, relativo a otro itinerario que discurra por este lugar. En este sentido, este itinerario ya constituye un antecedente, si no estamos equivocados. 
Por otra parte, tenemos otros antecedentes nuestros, en relación a las mineralizaciones presentes en esta zona. Se trata de MATA-PERELLÓ (1991a, 1991b y 1991c), dedicados a los inventarios mineralógicos de estas comarcas.

En relación con las características geológicas citaremos el trabajo de PEÑA et altri (1984). Asimismo, en relación al patrimonio geológico citaremos el trabajo publicado por la GADMA (2001).

Todos estos trabajos se hallaran debidamente relacionados en el apartado de REFERENCIAS BIBLIOGRÁFICAS, que figura al final del presente trabajo

\section{RECORRIDO DEL ITINERARIO}

Indicaremos, a continuación un itinerario que discurriría por diferentes lugares de la comarca anteriormente citada. Así, el recorrido se iniciará en Andorra (en la comarca de la Sierra de Arcos - Andorra), en donde se efectuará la primera parada.

Tras ello, se dirigirá hacía las cercanías de Alloza (en la mima comarca), sin llegar a la población. Así se seguirá por la carretera que conduce a las cercanías de Crivillén. En este tramo se efectuaran diversas paradas: una en el municipio de Alloza y las otras dos en el de Crivillén, concretamente en los Mases de Crivillén.

Luego, el recorrido se dirigirá hacía la Venta de la Pintada en cuyas cercanías se efectuará una nueva parada. Luego, el recorrido se encaminará hacía Ejulve, en cuyo término municipal se efectuaran las tres últimas paradas, tras sobrepasar el mencionado pueblo.

\section{DESCRIPCIÓN DEL ITINERARIO}

Como de costumbre, estructuraremos el recorrido del itinerario en una serie de PARADAS, que a continuación iremos viendo. En cada una de estas paradas haremos un breve comentario (geológico o mineralógico, según acontezca).

Por otra parte, en cada caso indicaremos (entre paréntesis) la hoja topográfica en donde se halla la parada. Para ello, utilizaremos las hojas del Instituto Geográfico y Catastral de España, publicadas a la escala de 1:50.000. En este caso, las dos hojas que utilizaremos serán las siguientes: 493 (o de Oliete), 494 (o de Calanda) y 518 (o de Montalbán).

Así pues, la relación de las paradas que componen el recorrido de este itinerario, son las siguientes:

PARADA 1. POZO DE SAN JUAN, (término municipal de Andorra, comarca de la Sierra de Arcos - Andorra). (Hoja 494).

El recorrido del presente itinerario geológico lo realizaremos en la población de Andorra, la capital de la comarca de la Serra de Arcos - Andorra. Desde la misma 
población, nos convendrá ir hasta el lugar en donde se halla el antiguo Pozo de San Juan. Para efectuar ahí la primera parada del recorrido, apenas a 1'5 Km de la población.

Andorra se encuentra sobre afloramiento de los materiales cenozoicos de la Depresión Geológica del Ebro, los cuales recubren a los mesozoicos (fundamentalmente cretácicos) de la Rama Aragonesa del Sistema Ibérico. Estos últimos afloran en las cercanías de Andorra.

En este lugar se hallaba un antiguo pozo minero, el denominado Pozo de San Juan, por el que se llegaba a los niveles mesozoicos situados bajo los cenozoicos. En concreto, se llegaba a los materiales cretácicos del Albiense, a los de la Formación Escucha, en donde se hallan los niveles lignitíferos explotados en diferentes lugares de la cuenca. Recientemente, los alrededores del pozo minero han sido muy bien habilitados como Museo de la Minería del Pozo de San Juan.



Otro aspecto del Museo Minero

(Fotografía de Kamal Tarquisti, Congreso de Ariño, 2010)

PARADA 2. MIRADOR DE ALLOZA, (término municipal de Alloza, comarca de la Sierra de Arcos - Andorra). (Hoja 494).

Después de realizar la parada anterior, cabe tomar la carretera que conduce hacía Alloza. A poca distancia de Andorra (a unos $3 \mathrm{Km}$ ) se encontrará un desvío por la izquierda que conduce a la Venta de la Pintada. Tomando esta carretera, tras recorrer unos $5 \mathrm{Km}$, llegaremos al Mirador de Alloza. En este lugar, a unos $9 \mathrm{Km}$ del Pozo de San Juan, efectuaremos una nueva parada.

En este recorrido habremos ido encontrando afloramientos de los materiales mesozoicos cretácicos; aunque estos se hallan recubiertos por terrenos cenozoicos del 
Eoceno y del Oligoceno, como ocurre en este lugar. Así pues, estos materiales son los que afloran en este lugar. Presentan tonalidades de color ocre, estando formados por niveles areniscosos y calcolutíticos.

Desde este lugar, mirando hacia el poniente, puede observarse la Hoya de Alloza, esculpida por la erosión de estos materiales cenozoicos. En el centro de la misma, se halla la población de Alloza.



Alloza y la Hoya de Alloza

PARADA 3. EXPLOTACIONES DE CAOLÍN DE LOS MASES DE CRIVILLÉN, (los Mases de Crivillén, término municipal de Crivillén, comarca de la Sierra de Arcos - Andorra). (Hoja 493).

Después de realizar la parada anterior, es necesario continuar por la carretera que conduce a las inmediaciones de Crivillén. Casi al llegar a la mencionada población, encontraremos un camino - carretero que conduce a las explotaciones de arcilla y a los Mases de Crivillén. Tomándolo, en unos $4 \mathrm{Km}$ llegaremos hasta las primeras explotaciones de caolín. Ahí efectuaremos una nueva parada, a unos $8 \mathrm{Km}$ de la anteriormente efectuada.

En este recorrido, habremos ido transitando entre afloramientos de los materiales cenozoicos que cubren a los mesozoicos, transitando siempre por el Sistema Ibérico, dentro de la denominada Rama Aragonesa, en donde nos encontramos en el lugar de la presente parada. 
En este lugar aparecen unos interesantes afloramientos de los materiales de la Formación Utrillas, del Albiense. Estos materiales cretácicos han sido explotados en este lugar para extraer el caolín.

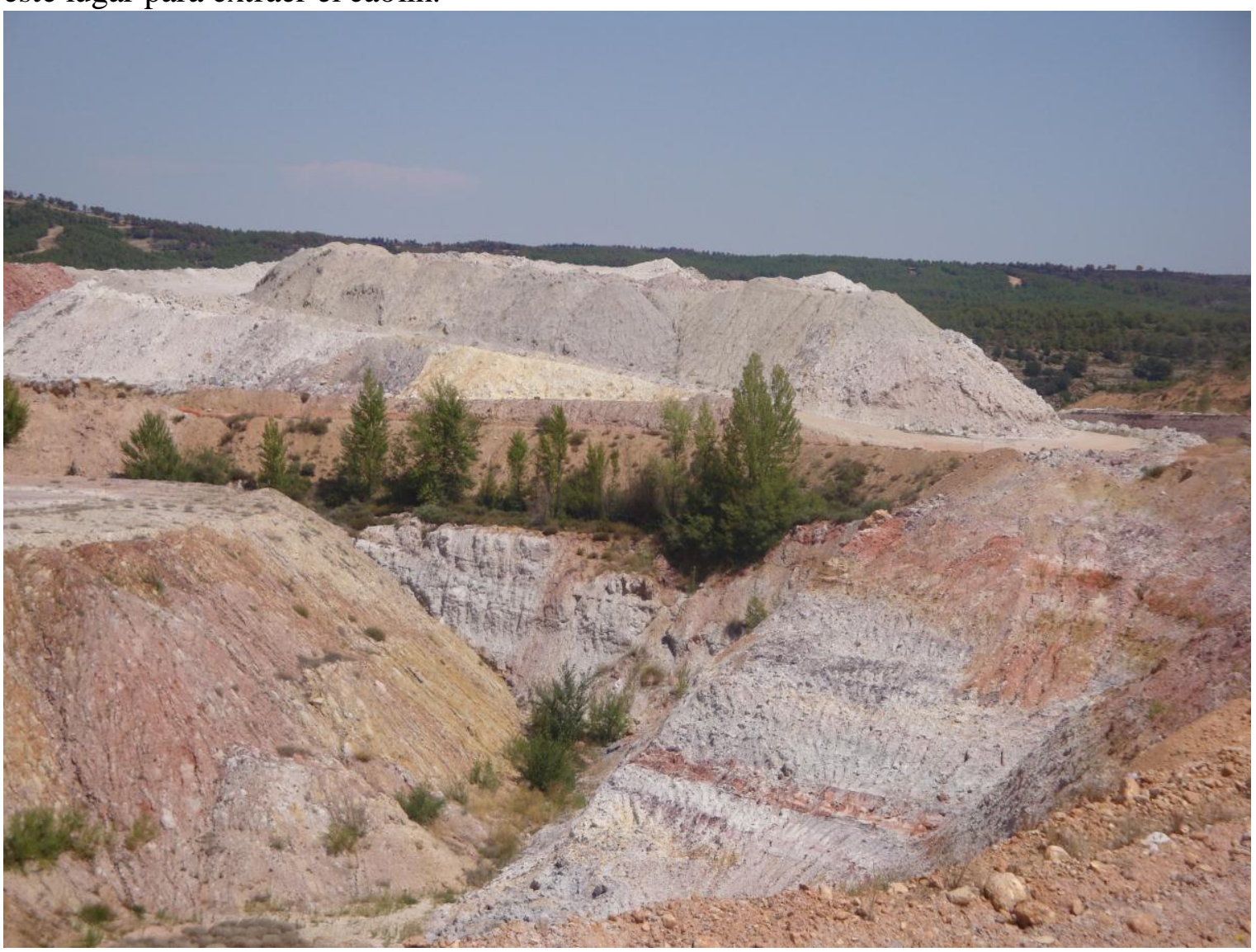

Explotaciones de caolín en los Mases de Crivillén

PARADA 4. MINAS DE MANGANESO DE LOS MASES DE CRIVILLEN, (los Mases de Crivillén, término municipal de Crivillén, comarca de la Sierra de Arcos - Andorra). (Hoja 493).

Tras realizar de la parada anterior, es necesario efectuar un breve recorrido, yendo primero a los Mases de Crivillén y posteriormente a las antiguas Minas de Manganeso de los Mases de Crivillén (o simplemente de Crivillén). Al llegar a ellas, a unos 0`2 Km de los mencionados Mases, efectuaremos una nueva parada, habiendo recorrido unos $2 \mathrm{Km}$ desde la anterior.

En este recorrido, habremos ido encontrando explotaciones de los caolines de la Formación Utrillas, semejantes a las de la parada anterior. Luego, al llegar a los Mases de Crivillén, habremos empezado a encontrar afloramientos de los materiales carbonatados cretácicos del Aptiense. Estos son los materiales que afloran en las inmediaciones de la parada.

En este lugar aparecen las escombreras (y algunos pozos) de las antiguas Minas de Manganeso de los Mases de Crivillén. Estas explotaciones se relacionan con unas mineralizaciones de relleno de cavidades de origen kárstico. Estas cavidades se hallan 
en unas calizas cretácicas del Aptiense, recubiertas por unos conglomerados cenozoicos del Oligoceno.

Entre los minerales presentes, cabe mencionar a los siguientes: BIRNESITA, MANGANITA, PIROLUSITA (el más abundante), PSILOMELANA, TODOROQUITA. Y también: GOETHITA (LIMONITA), HEMATITES y CALCITA. De entre ellos, el más abundante es la PIROLUSITA. Precisamente este mineral se presenta en ocasiones muy bien cristalizado, hasta el punto de que la PIROLUSITA de estas minas alcanzó una gran fama, entre los coleccionistas de minerales, por su extraordinaria belleza.

Por otra parte, junto a las minas existen unas interesantes viviendas trogloditas, en donde moraban probablemente los mineros y sus familias.

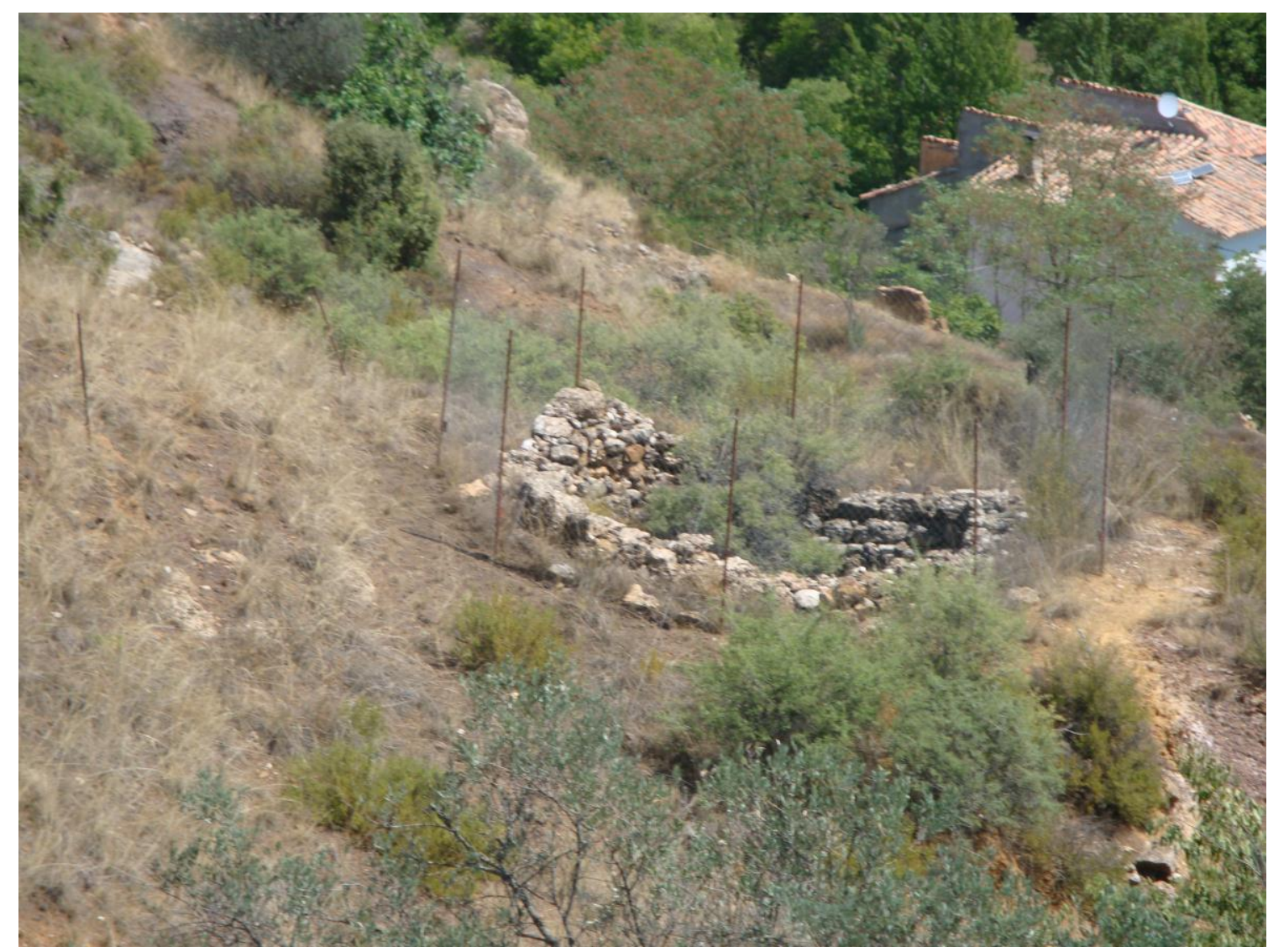

Uno de los antiguos pozos mineros de las Minas de Manganeso de los Mases de Crivillén

PARADA 5. EXPLOTACIONES DE CAOLÍN DE LA VENTA DE LA PINTADA, (término municipal de Gargallo, comarca de la Sierra de Arcos Andorra). (Hoja 493).

Después de realizar la parada anterior, será necesario retornar hasta las cercanías del pueblo de Crivillén y hasta la carretera que conduce a la Venta de la Pintada. Al llegar a ésta efectuaremos una nueva parada, a unos $6 \mathrm{Km}$ de Crivillén i a unos 10 de la parada anteriormente efectuada. 
En este recorrido, habremos ido encontrando afloramientos de los materiales mesozoicos citados en las paradas anteriores. Estos materiales del Sistema Ibérico, en donde ahora nos encontramos situados, son precisamente los que afloran en el lugar de la presente parada.

Efectivamente, en torno a la Venta de la Pintada se hacen ostensibles por doquier los materiales versicolores (de ahí posiblemente el nombre de la venta). Así, por doquier se observan los materiales de la Formación Utrillas, con tonalidades blancas, ocres, rojizas y pardas.

Estos materiales han sido explotados por encima de la Venta de la Pintada, en donde se halla la Muela Alta, para el aprovechamiento de los niveles caoliníferos, predominantes en los afloramientos.

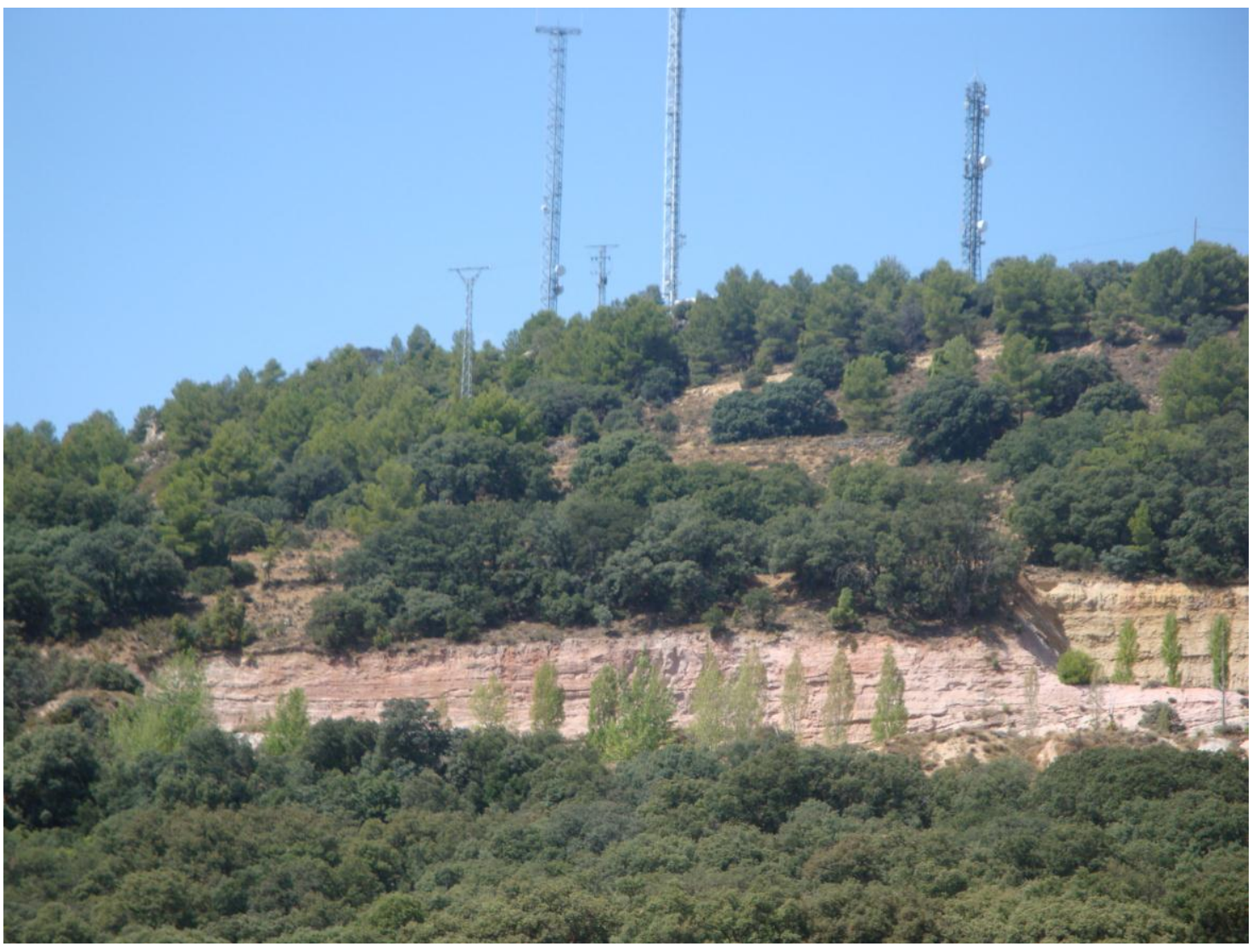

Antiguas explotaciones de caolín en la Muela Alta (la Venta de la Pintada, Gargallo)

PARADA 6. POLJÉ DE EJULVE, (término municipal de Ejulve, comarca de la Sierra de Arcos - Andorra). (Hoja 518).

Después de efectuar la parada anterior, cabe tomar la carretera que se dirige desde la Venta de la Pintada, hasta Aliaga. No obstante, a unos $9 \mathrm{Km}$ encontraremos la población de Ejulve, que superaremos. Poco después de la salida del pueblo, encontraremos por la derecha la carretera de la Zoma. Y poco después la de Cantavieja, por la izquierda. Nos convendrá seguir por ésta. A unos $4 \mathrm{Km}$ del inicio de esta carretera efectuaremos una nueva parada, tras recorrer unos $14 \mathrm{Km}$ desde la anterior. 
En este recorrido habremos ido encontrando afloramientos de los materiales mesozoicos, fundamentalmente cretácicos, que forman parte del Sistema Ibérico, en donde estamos situados desde el inicio del recorrido. Estos materiales, eminentemente carbonatados son los que predominan en el lugar de la presente parada, cerca del Mas de las Cofrarías.

En este lugar, mirado hacía el levante, es posible ver una gran planicie. Esta, corresponde a un poljé, similar al cercano de Hoya Pilar (de la vecina comarca del Maestrazgo).

Cabe decir que en torno de esta planicie, se observan afloramientos de los materiales mesozoicos carbonatados, circunstancia que pone de releve el carácter kárstico de esta zona.

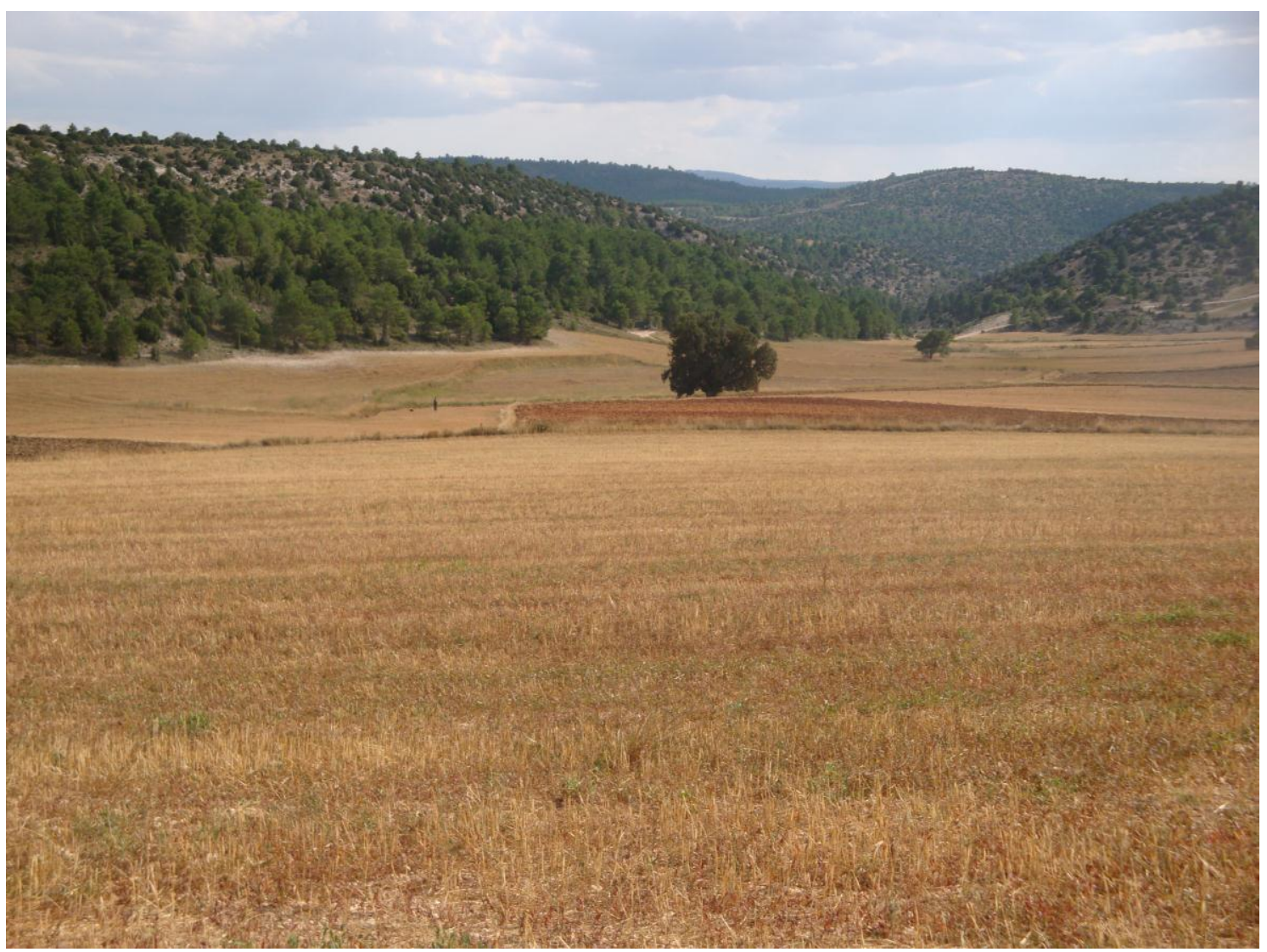

El Poljé de Ejulve

PARADA 7. CANTERA DE CALIZAS DE LA CARRETERA A CANTAVIEJA, (término municipal de Ejulve, comarca de la Sierra de Arcos - Andorra). (Hoja 518).

Tras efectuar la parada anterior, es necesario continuar por la carretera que conduce a Cantavieja. Sin embargo, al llegar a las cercanías del inicio del camino - carretero que conduce a Castellote, efectuaremos una nueva parada, a menos de unos $2 \mathrm{Km}$ de la anterior, hacía el Sur. 
En este recorrido habremos ido encontrando afloramientos de los materiales mesozoicos carbonatados, que en muy buena parte pertenecen al Cretácico, dentro siempre de la Rama Aragonesa del Sistema Ibérico, en donde ahora estamos situados. Precisamente, en este lugar hay un afloramiento de las calizas cretácicas del Aptiense.

Estas calizas han sido explotadas en este lugar. Así es fácilmente ostensible la cantera situada a la izquierda de la carretera, en donde se explotaron estas calizas con la finalidad de ser utilizadas como áridos para la construcción de viales.

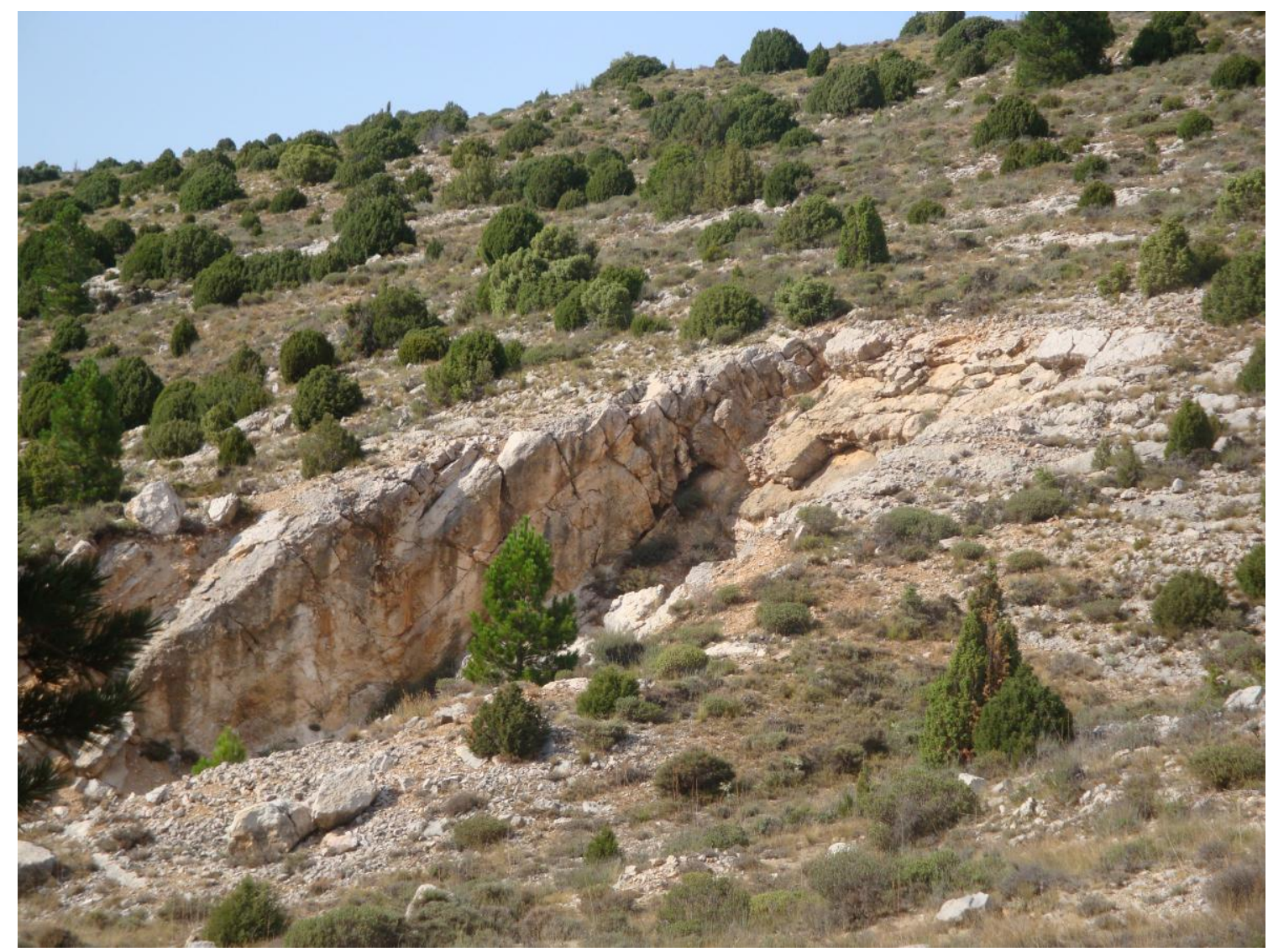

Cantera de la carretera a Cantavieja

PARADA 8. EL PILAR DE LOS BARRANCOS, (término municipal de Ejulve, comarca de la Sierra de Arcos - Andorra). (Hoja 518).

Tras efectuar la parada anterior, es necesario continuar por la carretera que conduce a Cantavieja. A unos 3'5 Km, encontraremos (por la izquierda) un camino que conduce hacía la Masía de los Barrancos. Deberemos tomar este camino, hasta llegar a las inmediaciones del Pilar de los Barrancos. Ahí efectuaremos una nueva parada, a unos 5 Km de la anterior.

En este recorrido, habremos ido encontrando afloramientos de los materiales mesozoicos citados anteriormente, predominando los niveles de calizas del Cretácico, como ocurre en este lugar. 
En efecto, en este lugar hay un afloramiento de los materiales mesozoicos del Cretácico. Cabe decir que en este lugar, como consecuencia de la erosión, se ha desarrollado un precioso pilar, al que hemos rebautizado con el nombre del Pilar de los Barrancos.

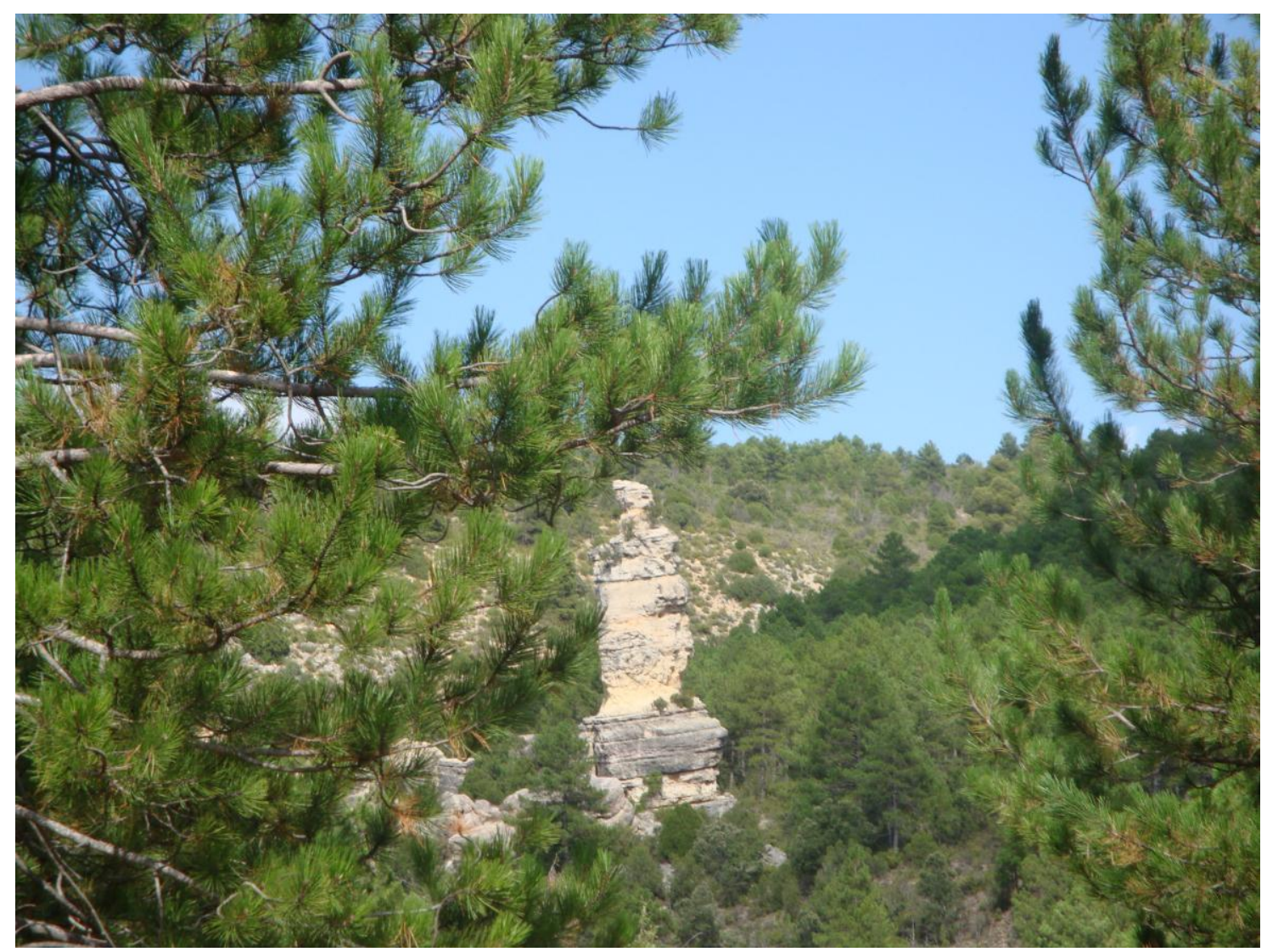

El Pilar de los Barrancos

\section{EN ESTE LUGAR FINALIZA EL RECORRIDO DEL PRESENTE ITINERARIO}

\section{BIBLIOGRAFIA}

CALVO, M. Et altri (1988).- Minerales de Aragón. Colección: temas geológicos, Edit. Mira, 210 pag. Zaragoza

GADMA. (2001).- Puntos de Interés Geológico de Aragón, Edit. Gobierno de Aragón, Departamento de Medio Ambiente (GADMA). 243 pag. Zaragoza

MAESTRE, A. (1845).- Descripción geognóstica del Distrito Minero de Aragón y Cataluña. Anales de Minas, t. III, Madrid 
MATA-PERELLÓ, J.M. (1987).- Introducción al conocimiento de las mineralizaciones aragonesas. Mineralogistes de Catalunya, t.III, pp. 258-265. Barcelona

MATA-PERELLÓ, J.M. (1991a).- Inventario Mineralógico de la comarca del Maestrazgo. Rodeno, no 33.15 pag. Manresa

MATA-PERELLÓ, J.M. (1991b).- Inventario Mineralógico de la comarca de la Tierra de Montalbán. Rodeno, n 35.34 pag. Manresa

MATA-PERELLÓ, J.M. (2002).- Recorrido geológico y mineralógico por la Tierra de Montalbán: desde Utrillas a la Zoma y al Parque Geológico de Aliaga. Inèdito.7 páginas. Manresa.

MATA-PERELLÓ, J.M. (2003).- Recorrido geológico y mineralógico por la Tierra de Montalbán y por el Maestrazgo: desde Utrillas y Escucha al Parque Geológico de Aliaga y a Cantavieja. Inèdito.7 páginas. Manresa.

MATA-PERELLÓ, J.M. (2009).- Recorrido geológico y mineralógico por las comarcas de la Sierra de Arcos - Andorra y del Bajo Martín: desde Andorra a Ariño y Albalate del Arzobispo. Inèdito. 12 páginas. Manresa

PEÑA MONGE, J.L. et altri (1984).- Geomorfología de la provincia de Teruel. Pub. Inst. Estudios Turolenses, 149 pag

PRAMES (2005).- Andorra - Siera de Arcos. Colección RUTASCAL por Aragón. Prames, Gobierno de Aragón. 119 pag. Zaragoza. 